- 0 


\section{A atuação do profissional de Relações Públicas no mercado da saúde: a no Hospital Samaritano
de São Paulo}

Cristina Ambrogi Leite Collina

- Especialista em Gestão Estratégica em Comunicação Organizacional e Relações Públicas (Gestcorp) pela Escola de Comunicações e Artes da Universidade de São Paulo (ECA-USP)

- Pós-graduada em Marketing pela Escola Superior de Propaganda e Marketing (ESPM)

- Bacharel em Relações Públicas pela Universidade de Taubaté

- Assessora de Comunicação Corporativa do Hospital Samaritano de São Paulo

- Finalista no Prêmio USP de Comunicação Corporativa 2006

- cristina.collina@samaritano.org.br 
ste relato tem a pretensão de apresentar um campo de atuação para o profis-
sional de comunicação, em especial de Relações Públicas, que até pouco tem-
po atrás vinha sendo pouco explorado e difundido, o mercado da saúde.

O intuito é também dar seguimento ao estudo A estratégia de comunicação e de Marketing como apoio à nova gestão hospitalar (COLLINA, 2001), apresentado no Curso de PósGraduação lato sensu de Gestão Estratégica em Comunicação Organizacional e Relações Públicas da Escola de Comunicações e Artes da Universidade de São Paulo (GestcorpECA-USP), além de mostrar como o profissional de Relações Públicas pode contribuir para sistematizar a Comunicação Integrada nas organizações hospitalares e fortalecer sua marca e imagem.

\section{A área hospitalar no Brasil}

Nos últimos anos, a política de saúde tem sido objeto de profundas discussões no âmbito da sociedade, com repercussão nos meios de comunicação. Esse tema tem promovido conflito entre o Estado e a comunidade.

O setor da saúde, que há décadas luta contra as dificuldades, busca sua sustentabilidade e ultrapassar as barreiras impostas por crises econômicas, instabilidades político-sociais, globalização, entre outros fatores.

O mercado de planos de saúde é o dínamo dessa mudança. Cerca de 35 milhões de brasileiros dispõem de convênio médico. Pacientes que arcam com o pagamento total dos serviços são raros. Até mesmo nos hospitais mais sofisticados, o público dos convênios responde por mais de $90 \%$ da ocupação. Os preços são altos para quem não conta com seguro saúde.

As regras ditadas pelos novos rumos profissionais obrigaram o mercado a tomar inúmeras ações que modificaram totalmente o sentido da atenção médica, especialmente nos últimos dez anos. A conscientização por parte da população de seus direitos como consumidores, ou seja, usuários de serviços, fez com que os hospitais reconhecessem a necessidade de melhorar os seus serviços, investir em tecnologias, otimizar os seus recursos e buscar profissionais cada vez mais capacitados. No segmento privado, estas alterações são ainda mais evidentes, pois os resultados comerciais são diretamente afetados pela concorrência. 
Instituições hospitalares privadas buscaram alternativas, como implantação de programas de qualidade, terceirização de atividades acessórias e contratos de gestão. Embora venham apresentando com isso sinais de prosperidade, ainda existem muitas limitações quanto ao entendimento e à utilização dos instrumentos de gestão e administração em saúde.

Os hospitais de primeira linha expõem a transformação do conceito de hospital no Brasil. Além de medicina de qualidade, centros médicos investem em conforto para pacientes e visitantes, em hotelaria. É certo que o paciente depende mais da competência médica que de hospitais luxuosos, mas o bom atendimento e a humanização hospitalar também pesam na recuperação.

Esse cenário fez com que hospitais privados de São Paulo buscassem no mercado profissionais de diversas áreas a fim de promover a profissionalização da gestão. Dentre elas, a área de comunicação. A comunicação vem ganhando posição estratégica nas empresas. As instituições desejam promover uma adequada, clara e eficiente comunicação com seus públicos. Com isso, passaram a investir recursos em estratégias de divulgação da sua marca, da sua imagem institucional.

Historicamente, o processo da comunicação na área da saúde foi fortemente evitado devido às questões éticas relacionadas à prática da medicina. Até o ano 2000, eram poucas as instituições de saúde brasileiras, como o Hospital das Clínicas, que mantinham em seu staff profissionais de Relações Públicas.

O Hospital é uma instituição sobremodo importante e proeminente numa comunidade, despertando muitos tipos de expectativas e sentimentos. A vizinhança mais próxima do hospital está preocupada com a aparência física, com a quantidade de barulho provocado pelas ambulâncias, com os problemas do lixo hospitalar e de estacionamento causados pelo tráfego do hospital e com a influência do hospital sobre os valores de imóveis. A comunidade em geral está preocupada com o fato de o hospital estar ou não aberto aos pacientes da comunidade, numa base não-discriminatória, se fornece um serviço de pronto socorro eficaz.

Diante dessa realidade, os hospitais, que durante muito tempo mantiveram-se fechados, passaram a compreender a importância de uma maior abertura, de manter seu público informado sobre suas atividades, ações sociais, investimentos. O hospital que deixar de comunicar seu posicionamento, trabalhar a prevenção de questões sobre a saúde da população ou que não desenvolver um programa de relacionamentos com os seus públicos, entre eles a mídia, poderá obter para si conseqüências muito negativas.

Nos últimos anos, as áreas de comunicação ou Marketing dos hospitais vêm crescendo. Com a criação da Associação Nacional dos Hospitais Privados (Anahp), que pro- 
A ATUAÇÃO DO PROFISSIONAL DE RELAÇÕES PÚBLICAS NO MERCADO DA SAÚDE: A EXPERIÊNCIA

NO HOSPITAL SAMARITANO DE SÃO PAULO - CRISTINA AMBROGI LEITE COLLINA

move encontros regulares das assessorias dos hospitais associados, isso ficou evidente. Percebe-se que, de 2000 até hoje, vários hospitais criaram uma área de comunicação em sua estrutura e a cada ano essas áreas vêm se solidificando.

\section{A experiência no Hospital Samaritano de São Paulo}

No Hospital Samaritano de São Paulo, a área de comunicação existe desde os anos 90, mas assumiu posição mais ativa a partir de 2000 , mediante a criação de uma Coordenadoria de Comunicação, ligada a uma Superintendência Comercial e de Marketing.

Nessa época, o hospital dava início ao processo de certificação pela Joint Commission International (JCI), um dos mais importantes órgãos mundiais dedicados à avaliação da qualidade das instituições de saúde.

Com a conquista da certificação, em 2004, que contou muito com o apoio da área de Comunicação na disseminação de uma nova cultura voltada para a qualidade, obteve-se a aprovação de um projeto de reestruturação e, assim, a área passou a se reportar administrativamente à Superintendência Geral, hoje Superintendência Corporativa.

A fim de se obter um melhor gerenciamento dos processos e um retorno mais efetivo no trabalho de fortalecimento da imagem institucional, os trabalhos foram divididos em:

- Organização de Comunicação Interna - administração dos veículos de comunicação e criação de campanhas motivacionais;

- Comunicação mercadológica - publicidade, comunicação visual, programas de relacionamento com os clientes, patrocínios e apoios; e

- Assessoria de imprensa e institucional - desenvolvimento de novos projetos e inovações. 
A ATUAÇÃO DO PROFISSIONAL DE RELAÇÕES PÚBLICAS NO MERCADO DA SAÚDE: A EXPERIÊNCIA NO HOSPITAL SAMARITANO DE SÃO PAULO • CRISTINA AMBROGI LEITE COLLINA

Cada uma dessas divisões é administrada por um profissional, mas toda a equipe interage para que haja o compartilhamento de experiências e opiniões. Dessa forma, todos participam e se sentem responsáveis pelo bom desempenho do serviço e o cumprimento das metas.

A equipe é composta por cinco profissionais com formação superior em Comunicação Social - Relações Públicas e Publicidade e Propaganda (uma assessora de comunicação, dois designers gráficos, dois analistas de comunicação), uma estagiária de Relações Públicas e uma auxiliar administrativo. Conta também com agências de comunicação para o relacionamento com a mídia e para o desenvolvimento de publicações e campanhas de Comunicação Interna, além de contar com uma agência de publicidade.

A Assessoria de Comunicação Corporativa adquiriu uma posição estratégica na empresa, participa do Grupo Executivo do Hospital, todos os anos elabora seu planejamento estratégico, com metas e verba orçamentária, e está inserida no planejamento estratégico do hospital.

Para maior assertividade nas ações, conquista de melhores resultados e implantação de melhorias, é realizada anualmente uma pesquisa de Comunicação Interna para analisar como está o processo de comunicação da área com o público interno, a comunicação interdepartamental e a comunicação entre chefia e os seus colaboradores diretos. Também são analisados os dados coletados na Pesquisa de Opinião Interna com Clientes e no Relatório de Manifestação Espontânea dos Clientes (elogios e sugestões), realizados pela Gerência de Relacionamento com o Cliente. Com base nesses relatórios, é elaborado um plano de oportunidades de melhorias dos serviços oferecidos pelo hospital. Serve também para divulgarmos os serviços e profissionais elogiados pelos clientes.

Em 2005, foi também realizada uma pesquisa de mercado (com fontes pagadoras, médicos, clientes, clientes em potencial e diretores de Recursos Humanos) a fim de iden- 
A ATUAÇÃO DO PROFISSIONAL DE RELAÇÕES PÚBLICAS NO MERCADO DA SAÚDE: A EXPERIÊNCIA NO HOSPITAL SAMARITANO DE SÃO PAULO - CRISTINA AMBROGI LEITE COLLINA

tificar a imagem institucional do hospital perante esses públicos. Com base nos dados da pesquisa, foi possível a elaboração e execução de um plano de oportunidades de melhorias. Uma nova pesquisa está programada para o início de 2008.

As atividades da assessoria envolvem o gerenciamento de:

- Comitê de Crise - elaboração de um manual de crise e o gerenciamento de situações que possam afetar a imagem da instituição perante a opinião pública;

- Assessoria de imprensa - programa de relacionamento com a mídia (media training; treinamento para equipe de linha de frente sobre como atender a imprensa; almoço entre a diretoria e editores de saúde; workshop sobre temas de interesse para jornalistas; envio de sugestão de pauta; atendimento a solicitação dos veículos; dentre outros);

- Administração da Comunicação Interna e dos veículos de comunicação

- Revista institucional O Samaritano com Você, lançada em 2007;

- Saúde Samaritano, encarte com dicas de saúde para a comunidade veiculado na Revista Higienópolis e na Revista Perdizes, que circulam nos respectivos bairros;

- Portal Corporativo (Internet e intranet);

- Café da manhã dos funcionários e médicos com a diretoria;

- Jornal Mural, lançado em 2007;

- Mural;

- Mensagens informativas no holerite dos colaboradores, no demonstrativo financeiro dos médicos e no fundo de tela dos computadores do hospital que estão conectados em rede;

- Comunicados on-line e divulgação on-line de clippings;

- Utilização de banners como uma ferramenta de comunicação.

- Campanhas internas - campanhas motivacionais para o público interno, como as campanhas de energia, do agasalho, reacreditação, dentre outras.

- Organização de eventos - organização de eventos científicos, culturais, sociais e esportivos que estejam ligados diretamente ao hospital;

- Publicidade - elaboração de plano de mídia, produção de anúncios e malas diretas.

- Programas de relacionamento com clientes - cartão de relacionamento Pra Você Samaritano (cartão de desconto para serviços e procedimentos realizados no hospital e em rede credenciada); comunidade judaica (comunidade residente no bairro Higienópolis, onde está localizado o hospital); paciente crônico; pacientes master; mídia; médicos; colaboradores; escolas da região; clientes (nascidos no hospital e após a alta hospitalar); comunidade local; fontes pagadoras e autoridades.

- Comunicação visual - implantação da padronização de toda a comunicação visual do hospital (sinalização, uniformes e materiais gráficos, como papelaria, folders, banners, malas diretas etc.).

- Patrocínio e apoios - a eventos realizados por outras instituições, mas que estejam ligados às atividades científicas na área da saúde, esportiva para a promoção da saúde ou de cunho social.

- Desenvolvimento de projetos e estudos - estudo de posicionamento estratégico; 
estudo de revitalização da marca; responsabilidade social; indicadores de performance, hotelaria, maternidade (programa de divulgação da maternidade como unidade de negócio), dentre outros.

Uma das maiores preocupações da área, até em função da certificação internacional, se relaciona ao acompanhamento de indicadores e à mensuração dos resultados. São exemplos de indicadores de resultado e de processo:

- Portal corporativo - avaliação qualitativa e quantitativa dos acessos mensais e do conteúdo acessado;

- Assessoria de imprensa - avaliação qualitativa e quantitativa das matérias veiculadas sobre o Samaritano na mídia (quantidade em relação ao tipo de veículo e tipo de pauta);

- Avaliação do nível de satisfação dos serviços prestados pela Assessoria de Comunicação - avaliação aplicada após a realização de cada campanha ou evento para medir a satisfação dos clientes internos;

- Pesquisa de Comunicação Interna, pesquisa de mercado e pesquisa de opinião interna com clientes (Gerência de Relacionamento com Cliente).

Como resultado do trabalho da Assessoria de Comunicação, pode-se destacar o crescimento de $370 \%$ no número de acessos do portal e de $312 \%$ da intranet, desde sua implantação, em 2002; o número de matérias veiculadas na mídia sobre o hospital, que cresceu mais de $365 \%$, passando de 169 matérias, em 2001, para 626, em 2006; o aumento do número de pacientes da comunidade judaica atendidos no hospital, de 6 em 2001, para 30 pacientes/dia em 2006.

Além disso, a pesquisa interna de comunicação apontou que os colaboradores sentiram a melhora na comunicação após o processo de reestruturação da área. Em relação à pesquisa de opinião externa, a análise possibilitou a elaboração e execução de um plano de oportunidades de melhorias.

O trabalho desenvolvido pela área vem obtendo destaque no mercado. Como conseqüência, o modelo adotado no Samaritano tornou-se referência para outros hospitais e a instituição recebe anualmente visitas de profissionais de comunicação de outras instituições e empresas para benchmarking. Entre 2005 e 2006, a área recebeu convites para proferir palestras no Gestcorp-ECA-USP; no seminário Comunicação Interna com o case Reestruturação da Assessoria de Comunicação do Hospital Samaritano, promovido pelo International Business Communications (IBC); no seminário de Marketing Hospitalar, promovido pela mesma instituição, com o case Marketing de Relacionamento e no congresso de Marketing em Saúde, promovido na Adh'2006 pelo Centro Universitário São Camilo - Hospitalar, com as palestras Fidelização de Clientes e Como a Certificação pode impactar a imagem da Instituição. Em 2007, o Hospital Samaritano participa da comissão organizadora deste último curso, promovido pela Adh, o maior congresso de administração hospitalar do País. 
A ATUAÇÃO DO PROFISSIONAL DE RELAÇÕES PÚBLICAS NO MERCADO DA SAÚDE: A EXPERIÊNCIA NO HOSPITAL SAMARITANO DE SÃO PAULO - CRISTINA AMBROGI LEITE COLLINA

A Assessoria de Comunicação Corporativa concedeu entrevistas para revistas e jornais sobre media training; portal corporativo; diferenciais da maternidade; projetos de humanização; indicadores; a nova identidade visual do hospital; dentre outros. A assessora foi ainda convidada a escrever o capítulo A reestruturação da área de comunicação no Hospital Samaritano, no terceiro volume da Coleção Inteligência, da Aberje (Associação Brasileira de Comunicação Empresarial), Comunicação empresarial: estratégia de organizações vencedoras (no prelo); o capítulo Marketing de relacionamento no Hospital Samaritano, no livro Marketing de Serviço: fundamentos, análises e prática no setor da saúde, coordenado pelo Prof. Severino Francisco da Silva, da Universidade Federal de Alagoas, em elaboração.

Em 2006, o Hospital Samaritano foi finalista no Prêmio USP de Comunicação Corporativa, organizado pela ECA-USP, com o case Reestruturação da área de comunicação do Hospital Samaritano, motivo de muito orgulho, pois indica que a área está no caminho certo no desenvolvimento de uma comunicação clara, ética e integrada com os públicos do hospital.

Com muito trabalho, criatividade e disposição, a Assessoria de Comunicação tem conquistado uma posição estratégica na instituição, mediante o acompanhamento dos projetos desde a sua elaboração até sua implantação. Com isso, tem sido possível objetivar um ganho de eficiência e produtividade no lançamento de novos projetos, campanhas e, consequentemente, na obtenção de melhores resultados.

O grande desafio que por ora se apresenta é a consolidação da nova identidade visual do Hospital Samaritano, lançada no final de 2006 - uma marca que simboliza o momento atual de modernização e crescimento do hospital e a construção de um novo prédio hospitalar, a ser erguido nas atuais instalações do hospital, que irá dobrar sua capacidade física. O plano de comunicação deste projeto foi lançado em março de 2007.

Frente ao exposto, pode-se afirmar que existe para os profissionais de comunicação um novo e promissor mercado, basta muita criatividade, disposição e um olhar para o futuro.

\section{Bibliografia}

KUNSCH, Margarida Maria Krohling. Relações públicas e modernidade: novos paradigmas na comunicação organizacional. São Paulo. Summus, 1997 (Coleção Novas Buscas em Comunicação 56).

KOONTZ, Harold; O'DONNELL, Cyrill. Princípios de administração: uma análise das funções administrativas. Vol. 1, 13. edição. Trad. Albertino Pinheiro e Ernesto d’Orsi. São Paulo: Pioneira, 1982. p. 207.

KOTLER, Philip. Marketing para organizações que não visam o lucro. 4. ed. São Paulo: Atlas, 1994. p. 310-331. 
A ATUAÇÃO DO PROFISSIONAL DE RELAÇ̃̃ES PÚBLICAS NO MERCADO DA SAÚDE: A EXPERIÊNCIA

NO HOSPITAL SAMARITANO DE SÃO PAULO • CRISTINA AMBROGI LEITE COLLINA

COLLINA, Cristina Ambrogi. A estratégia de comunicação e de marketing como apoio à nova gestão hospitalar. Monografia (Especialização em Relações Públicas) - Escola de Comunicações e Artes. São Paulo: Universidade de São Paulo, 2001.

GASPARETTO Jr., Renato. Nossos desafios já estão globalizados. Revista Comunicação Empresarial - Aberje. São Paulo: ano 9, n. 32, $3^{0}$ trimestre de 1999.

Saúde cinco estrelas - hospitais investem em conforto e alta tecnologia para atender à demanda dos planos de saúde. Revista Época. São Paulo: ed. 149, 12 de março de 2001.
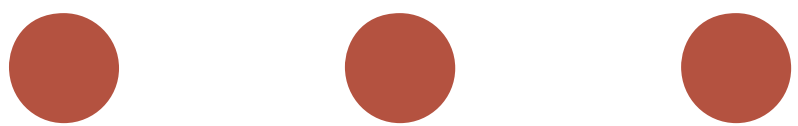